\title{
The Proportional Design in Rudolph M. Schindler's Braxton-Shore House of 1930
}

\author{
Jin-Ho Park*1 and Hong-Kyu Lee ${ }^{2}$ \\ ${ }^{1}$ Associate Professor, Department of Architecture, Inha University, Korea \\ ${ }^{2}$ Full-time Lecturer, Department of Architecture, Daelim College, Korea
}

\begin{abstract}
The Braxton-Shore house has been considered as an exemplar of 'space architecture' - an architecture of 'space forms' which R. M. Schindler believed distinguished his work from contemporary functionalists and internationalists. To achieve such' space architecture', Schindler utilized a proportional system of a space reference frame as a mental tool. This paper first outlines the spatial scheme of the Braxton-Shore house, explains Schindler's space reference frame, and finally interprets the proportional design of the house in analogy with the 'row' system, the Fibonacci and Lucas sequence, and musical ratios.
\end{abstract}

Keywords: Schindler; proportion; 'row' system; the Fibonacci and Lucas sequence; musical ratios

\section{Introduction}

Most writings on the proportional study of Rudolph Michael Schindler's houses have been descriptive observations rather than in-depth analyses using computational techniques or making pedagogical inferences. At times, the significance of the architect's proportional system has been blatantly ignored. Architectural historians, like David Gebhard (1971), considered Schindler's system merely one practical tool for wood frame structure and construction. It is true that Schindler's unit system was derived from practical needs for his space architecture, but it may be a mistake to consider the system without its theoretic implications. In a paper by March (1993a), Schindler's proportional method was interpreted as an analogy with classical proportion, much more than a mere construction tool for the first time. When March (1993b) used a musical analogy to examine the proportional design of the How house; in his paper, 'Dr. How's Magical Musical Box' he seems to portray 'architecture as frozen music.'

Recently, Park (2003) interpreted Schindler's 'reference frames in space' as set forth in his 1916 lecture notes on mathematics, proportion, and architecture, relating to the theory of 'row' in the context of John Beverley Robinson's articles in the Architectural Record (1898-1899). In a complementary paper in the same issue of the Nexus Network Journal:

\footnotetext{
*Contact Author: Jin-Ho Park Ph.D., Associate Professor, Department of Architecture, Inha University

\#253 Yonghyun-dong, Nam-gu, Incheon 402-751 Korea

Tel: +82-32-860-7597 Fax: +82-32-866-4624

E-mail: jinhopark@inha.ac.kr

(Received October 8, 2008 ; accepted January 6, 2009)
}

Architecture and Mathematics, March (2003) examines the mathematics that underlie Schindler's notion of the 'row'.

Schindler argues in his proportional system of space reference frame that the space architect needs to not only improve his mental image of the space, but also possess a proportional system. With the system, the forms of space are freely conceived and precisely measured in the architect's mind. Forms of space are envisioned 'by being inside of it', just as musicians imagine and articulate their music with notes.

By 1930, Schindler had sufficient command of his system in organizing his space and space forms to propose a beach house for Mr. And Mrs. Henry Braxton in Venice Beach, Los Angeles. Although Schindler left behind numerous built and unbuilt projects which demonstrate extraordinary spatial complexity as well as variety, the Braxton-Shore house stands out the most. Unfortunately, it was never built, due to the client's financial circumstances at the design stage (Park and March, 2003).

\section{Spatial Scheme of the House}

The spatial scheme of the house consists of three organizational forms - a garage, the residence, and the circulation spine. The circulation spine, which is composed of five horizontal wooden structures, connects the house and the garage. Rather than using concrete, as in the Lovell house of 1928, these structures are made of wooden frames. All space volumes of the house are interlocked along the five major structures.

A courtyard covered with sand occupies the space between the house and the garage. The rectilinear box form dominates its spatial outlook, in Gebhard's words, ' ...[a] rectangular box into and out of which secondary 


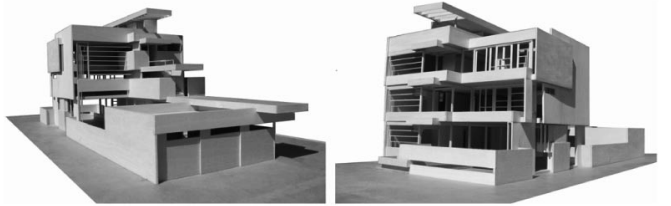

Fig.1. 1/4 Scale Reconstruction of the Braxton-Shore House, 1930

volumes projected,' and in Giella's words, 'a slightly top-heavy composition is created by cantilevering out each successive story from bottom to top.' Various box forms are projected, recessed, and interlocked along the longitude axis (Fig.1.). It is Schindler's usual practice and the signature of his designs.

The ground level preserves an open playground and patio for the natural beach sand, forecourt, outdoor fireplace, garage, guestroom, maid's quarters, and furnace (Fig.2.). The ground level is an independent unit, and there is no interior staircase connecting the ground to the upper level. A major portion of the house is raised above the lot. The option of the lifted structure may be suitable for the beach house by the necessity of allowing the sun and air to reach the entire floor, preserving some part of the site beneath for a playground, and providing an open outlook to the ocean.

On the main level, the architect created a living room two stories in height. It is open to the Pacific Ocean and enclosed by individual bedrooms on the balcony floor overlooking the living area. Below is the living room, kitchen facilities, dining room, and porches are adjacent to the dining room and kitchen. Inside the main floor, there is little built-in furniture shown on the drawing compared to his other projects so that the inner space remains visually unobstructed. In addition,

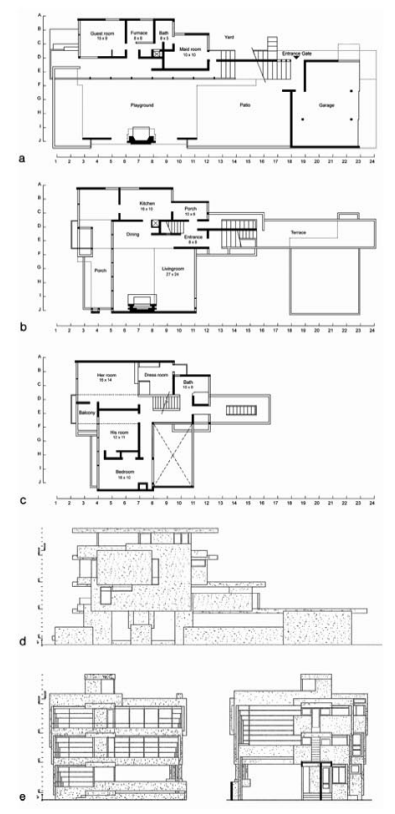

Fig.2. Floor Plans and Elevations of the Braxton-Shore House (1930) with the 4-foot Square Unit Grid. From Top to Bottom: Ground Floor Plan, Main Floor Plan, Balcony Floor Plan, South Elevation, and West and East Elevations finely proportioned window mullions are inset facing the courtyard, while door mullions face the ocean side. The three bedrooms on the balcony floor are disposed equally overlooking the Pacific Ocean. The composite roof is used as a terrace; a portion of it is used for sunbathing, a sleeping porch, and a small closet.

\section{References Frames in Space}

Although Schindler expressed his early interest in a proportional system as early as 1916, it was not clearly expressed until 1946 when Schindler published a comprehensive summary of his proportional system in an article, 'Reference Frames in Space' (Schindler, 1946). In the article, his idea of proportion is well defined as follows: 'Proportion is an alive and expressive tool in the hands of the modern architect who uses its variations freely to give each building its own individual feeling.' The system for Schindler is indispensable to the creation of his notion of space architecture as a doctrine of spatial organization. Schindler argued that he started using the system as early as 1920. In fact, an analysis of Schindler's Free Public Library project of 1920 demonstrates his use of the system (Park, 1996).

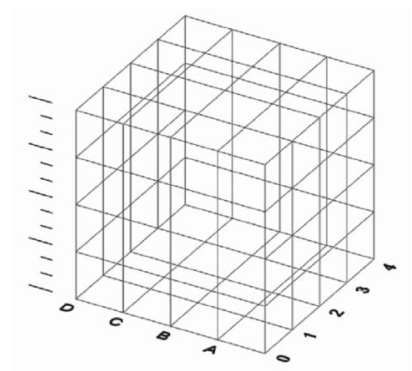

Fig.3. Schindler's Three-dimensional Grid of Space Cubes

The purpose of Schindler's system is to provide a mental structure for conceptualization before pencil meets paper, and, secondly, to communicate to the builders a map locating elements, allowing them to easily scale off dimensions. As such, all locations and sizes of the parts with respect to the whole are precisely identified during the construction process. Thus, no obscure or arbitrarily unrelated measurements are involved in the unit system. In addition, the unit grid system offers the means to visualize 'space forms' in three dimensions. He argued, ' $\ldots$ it must be a unit which he can carry palpably in his mind in order to be able to deal with space forms easily but accurately in his imagination.' Although there are a few exceptions, like the Schindler Shelter project where he used a 5-foot unit module, Schindler recommended 4-foot module as the basic unit, to be used with simple multiples and with $1 / 2,1 / 3$, and $1 / 4$ subdivisions. Among the subdivisions, with only a few exceptions, $1 / 3$ and $1 / 4$ are used for vertical modules in his works. This single unit module with its multiples and subdivisions form the basis of all dimensions of rooms in a cube form (Fig.3.). 
There are two reasons for this choice. First, the unit must be related to the human figure to satisfy all the necessary sizes for rooms, doors, and ceiling heights; second, for practical reasons, the 48 -inch module fits the standard dimensions of materials and common construction methods available in California at that time. He utilized his unit system in a square grid pattern. Numbers and letters are laid out on the grid on the floor plans in sequence and the vertical module is identified with an elevation grade (Fig.3.).

The grid was presented on drawings and on the house in his earlier designs, yet they disappear from the house and, at times, from the drawings. However, this does not mean he abandoned his system; on the contrary, his system remains embedded in the designs as an underlying principle. In addition, Schindler used the system to measure rooms. In his preliminary sketches, his room sizes, with the whole numbers on drawings, are commonly presented. These numbers are increments of unit multiples with their subdivisions.

\section{Proportional Analysis of the House}

Unlike the proportional study of the Lovell house of 1925-26 by Sarnitz (1986, 1988), the proportions of the Braxton-Shore house has remained uninvestigated. Sarnitz's analysis of the Lovell house plans and elevations is based on his belief that a simple square and double square determine the overall proportional system of the house.

There are various sets of drawings of the house in the Schindler Archive at the University of California at Santa Barbara ${ }^{1}$, including preliminary sketches, structural and sash details, construction drawings, and well-organized presentation drawings. These sources provide valuable information for the proportional analysis of the house.

On the drawings, dimensions and placements of various spatial forms and details of the house are controlled by Schindler's unit system (Fig.2.). The 4-foot unit system is clearly identified in the plan with numbers and letters, and the 16-inch vertical module in elevation with grades. All major space, details, and structure underlie its subdivisions and multiples where all parts are related to each other in terms of simple unit relations to produce a coherent unity. Most of the major rooms in the construction drawings are measured in whole numbers and written on the drawing as is common in other designs. Although rooms are frequently not a simple rectangular form, Schindler approximated those to the whole numbers. It appears that simple whole numbers with respect to the space reference frame easily grasp its size, as Schindler implied in his space reference frame system.

Given the evidence of the floor plan, the dimensions of the rooms include the following: a 9-foot $x$ 15-foot guestroom, 10-foot x 10-foot maid room, 5-foot $\mathrm{x} 8$-foot bathroom, 6-foot $\mathrm{x} 8$-foot furnace on the ground level, 24-foot $\mathrm{x} 27$-foot living room, 10-foot $\mathrm{x}$ 16-foot the kitchen, 6-foot $x$ 10-foot porch in front, an 8 -foot $\times 8$-foot entrance on the second level, his room 11 -foot x 12-foot, her room 14-foot x 16-foot, and another 10-foot $\times 16$-foot bedroom on the third floor. The rafters of the horizontal wooden structures are regulated in a 2-foot distance - half of the unit module.

However, room dimensions written on the construction drawings are found to be inconsistent with the real dimensions of the rooms. The construction documents of Schindler provided actually consist of drawings which other architects might consider schematic, like the instructions to the builder.

Two reasons for this might be considered. First, this difference relies on their stages of design development, either conceptual or practical, that are common practice in the architectural field. Early schematic designs are primarily a conceptual basis, and they evolve depending on specific practical requirements in the design process and during fabrication as well as construction. Thus, room sizes shown on the drawings do not always accord with dimensions measured from the drawings, although the former might be what the architect initially had in mind; rather, the latter is the result of some adjustments. For example, in the Braxton-Shore house, the dimensions of the guestroom shown on the drawing are 15-foot by 9-foot, yet the real measure of the drawing of the room is 14-foot by 11-foot. Before arriving at a final scheme of a project, exercises of various possible schematic layouts are an almost universal procedure employed by architects, including Schindler.

Second, various rooms are not rectangular, but interlocked, overlapped, and, at times, zigzagged. In this case it is not possible to present a simple dimensional relationship of room ratios with two terms $\mathrm{a}$ and $\mathrm{b}$, to $\mathrm{a}: \mathrm{b}$, or $\mathrm{a} \mathrm{x} \mathrm{b}$, other than by approximation. In fact, Schindler approximately measured the room sizes in a rational manner with his unit system to determine its size of each room and probably their proportional relations.

Although these inconsistencies may cause confusion for this analysis, the collection of room dimensions serves as an excellent basis for further explorations of his proportional designs (Table 1.). This proportional analysis solely relies on the architect's room dimensions written on the drawings since it maintained the architect's original intent of room sizes and their relations to each other before the architect's transfer of the ratios to the practical necessities.

Table 1. provides interesting results on two levels. On one hand, among three fractions that Schindler used, which include $1 / 2,1 / 3$, and $1 / 4,1 / 3$ of 48 inches (16-inch) is not used in room dimensions of the plan. Instead, the fraction is used only for the vertical module. The 16-inch vertical module measures the room height of the house. It also governs window mullions, door mullions, and the thickness of a series of horizontal structures. Accordingly, it is inferred 
Table 1. List of All Rooms and their Relations

\begin{tabular}{|c|c|c|c|c|c|}
\hline Floor & Room Names & Room Dimensions & Space Reference Frame & Ratios & Decimal Value of the Ratios \\
\hline Ground Floor & Guestroom & $15 \times 9$ & $33 / 4 \times 21 / 4$ & $5: 3$ & 1.67 \\
\hline & Maid room & $10 \times 10$ & $21 / 2 \times 21 / 2$ & $1: 1$ & 1.00 \\
\hline & Bathroom & $8 \times 5$ & $2 \times 1 \frac{1}{4}$ & $8: 5$ & 1.60 \\
\hline & Furnace & $8 \times 6$ & $2 \times 1 / 2$ & $4: 3$ & 1.33 \\
\hline Second Floor & Living room & $27 \times 24$ & $63 / 4 \times 6$ & $9: 8$ & 1.125 \\
\hline & Kitchen & $16 \times 10$ & $4 \times 21 / 2$ & $8: 5$ & 1.60 \\
\hline & Porch & $10 \times 6$ & $21 / 2 \times 1 \frac{1}{2}$ & $5: 3$ & 1.67 \\
\hline & Entrance & $8 \times 8$ & $2 \times 2$ & $1: 1$ & 1.00 \\
\hline Third Floor & His room & $12 \times 11$ & $3 \times 23 / 4$ & $12: 11$ & 1.09 \\
\hline & Her room & $16 \times 14$ & $4 \times 3 \frac{1}{2}$ & $8: 7$ & 1.14 \\
\hline & Bedroom & $16 \times 10$ & $4 \times 21 / 2$ & $8: 5$ & 1.60 \\
\hline & Bathroom & $10 \times 6$ & $21 / 2 \times 1 \frac{1}{2}$ & $5: 3$ & 1.67 \\
\hline
\end{tabular}

Table 2. Series of Coprime Room Dimensions where the Two Dimensions are Prime to One Another

\begin{tabular}{|c|c|}
\hline Row & Ratios \\
\hline Row-1 & $1 \times 2,2 \times 3,3 \times 4,4 \times 5,5 \times 6,6 \times 7,7 \times 8,8 \times 9,9 \times 10,10 \times 11,11 \times 12, \ldots$ \\
Row- & $1 \times 3,3 \times 5,5 \times 7,7 \times 9,9 \times 11,11 \times 13,13 \times 15,15 \times 17,17 \times 19, .$. \\
Row-3 & $1 \times 4,2 \times 5,4 \times 7,5 \times 8,7 \times 10,8 \times 11,10 \times 13,11 \times 14,13 \times 16, \ldots$ \\
Row-4 & $1 \times 5,3 \times 7,5 \times 9,7 \times 11,9 \times 13,11 \times 15,13 \times 17,15 \times 19,17 \times 21, \ldots$ \\
Row-5 & $1 \times 6,2 \times 7,3 \times 8,4 \times 9,6 \times 11,7 \times 12,8 \times 13,9 \times 14,11 \times 16,12 \times 17, \ldots$ \\
Row-6 & $1 \times 7,5 \times 11,7 \times 13,11 \times 17,13 \times 20,17 \times 23,19 \times 25,23 \times 29, \ldots$ \\
Row-7 & $1 \times 8,2 \times 9,3 \times 10,4 \times 11,5 \times 12,6 \times 13,8 \times 15, \ldots 13 \times 20,15 \times 22, .$. \\
Row-8 & $1 \times 9,3 \times 11,5 \times 13,7 \times 15,9 \times 17,11 \times 19,13 \times 21,15 \times 23, \ldots$ \\
Row-9 & $1 \times 10,2 \times 11,4 \times 13,5 \times 14,7 \times 16,8 \times 17, \ldots 10 \times 19,11 \times 20,13 \times 22, \ldots$ \\
\hline
\end{tabular}

that Schindler used those fractions separately: 12" increments for plans and those of 16 " for elevations.

The door height is his typical 6 feet 8 inches. The room heights vary, but they are subdivisions and multiples of 16 inches vertical modules. The room height of the ground floor, including the maid, guestroom, furnace, and garage, is 8 feet, but the height of the open playground is 10 feet. The height of the kitchen and the dining room in the second floor is 8 feet. The height of the two-story high open living room is 14 feet 16 inches. The height of His room and another bedroom is 8 foot 16 inches on the third floor. The height of Her room is 9 foot 8 inches, but that of the bathroom and the dressing room next to Her room are an exceptional 8 feet 10 inches. A series of five horizontal structures are 8 feet apart, except for the height of the first floor, which is 8 feet 9 inches.

On the other hand, unlike the complexity of the space forms, surprisingly few room dimensions and corresponding ratios are involved; yet their interrelationship are worthy of the profound study. In the house, twelve different room dimensions and seven different ratios, 1:1, 4:3, 5:3, 8:5, 8:7, 9:8, and $12: 11$, are collected. In order to deduce relationship of dimensions and ratios, particular analytic methods are introduced to derive all these ratios.

\subsection{The 'row' system}

The room dimensions of the house are inclusive within Schindler's early notion of 'row'. Schindler used the term 'row', a sequence, 'a following of unequal units with definite changes' (Park, 2003, March 2003). A page from Schindler's 1916 lecture notes ${ }^{2}$ illustrates a particular 'row', which is equivalent to the classical sequence of subsuperparticular numbers (March, 1998a). If $\mathrm{a} / \mathrm{b}$ is a term in the 'row', the next term is (a $+1) /(b+1)$. Schindler's use of the term 'row,' appears to derive from his association with the circle around Adolf Loos from Vienna. March (2003) generalized the theory of 'row,' by classifying a series of 'rows' in the coprime rectangles (Table 2.).

All room dimensions of the Braxton-Shore house are to be classified according to the 'row' system. The row-0 contains two room sizes, which involve a 1:1 ratio. Row-1 also contains two room sizes from the house,

$$
2 / 1,3 / 2,4 / 3,5 / 4,6 / 5, \ldots, \underline{9 / 8}, 11 / 10, \underline{12 / 11}, \ldots
$$

Row-2 contains another two room sizes:

$$
3 / 1,4 / 2,5 / 3,6 / 4,7 / 5, \underline{8 / 6}, 9 / 7, \ldots, \underline{16 / 14}, \ldots
$$

The alternate $14 \times 11$ room belongs to row-3 along with $27 \times 24$ and $8 \times 5: 14 / 11=(4+10) /(1+10), 27 / 24$ $=(4+23) /(1+23), 8 \times 5=(4+4) /(1+4)$. By continuing the process, the dimensions of all the rooms are summarized as the following six row equivalences:

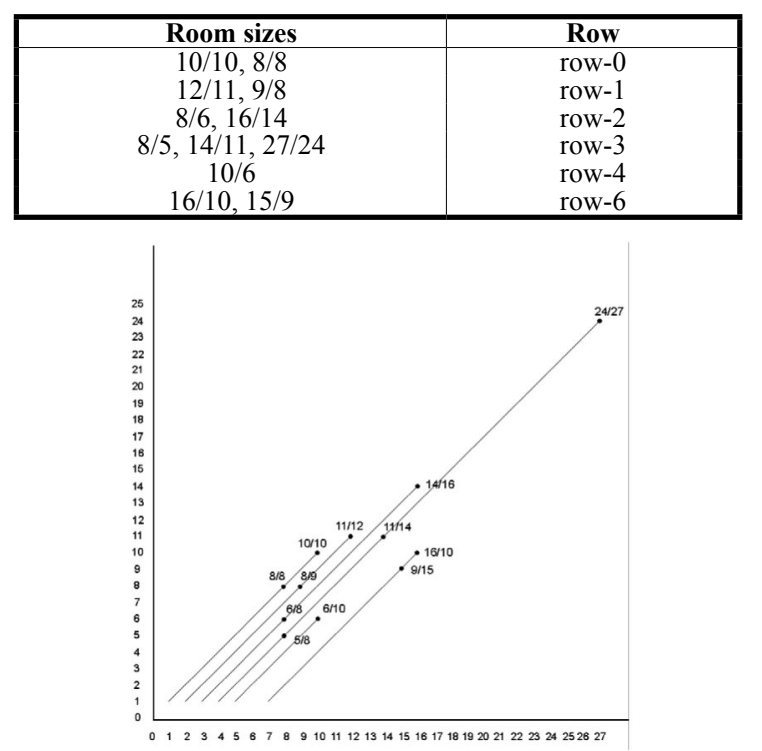

Fig.4. Plot of Room Sizes in the Braxton-Shore House Classified by 'Rows'. From Left to Right, First Row 1/2, Second Row 1/3, Third Row 1/4, Fourth Row 1/5, and Sixth Row 1/7. 
These room sizes are also to be classified according to the regulating principle, or geometric similarity. A total of 8 different equivalences are provided, as shown below. These ratios are further interpreted in terms of their proportional relationships in the following two sections.

\begin{tabular}{|l|l|}
\hline Room sizes & Ratios \\
\hline $10 \times 10,8 \times 8$ & $1: 1$ \\
$8 \times 6$ & $4: 3$ \\
$10 \times 6,15 \times 9$ & $5: 3$ \\
$8 \times 5,16 \times 10$ & $8: 5$ \\
$16 \times 14$ & $8: 7$ \\
$9 \times 8,27 \times 24$ & $9: 8$ \\
$12 \times 11$ & $12: 11$ \\
$14 \times 11$ & $14: 11$ \\
\hline
\end{tabular}

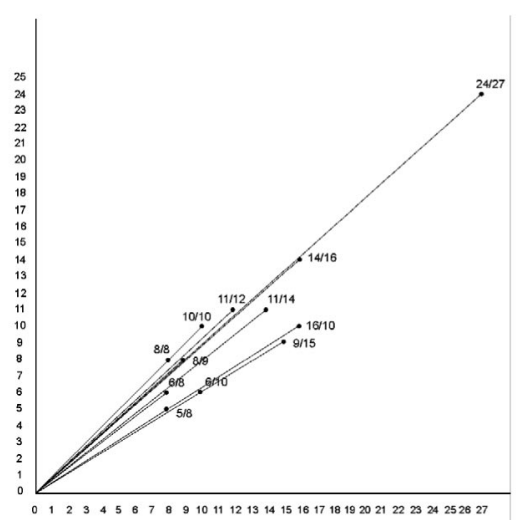

Fig.5. Plot of Room Sizes in the Braxton-Shore House Classified by Conventional Ratios. Clockwise, First Ratio 1:1, Second Ratio 11:12, Third Ratio 8:9, Fourth Ratio 7:8, Fifth Ratio 3:4, Six Ratio 8:5, and Seventh Ratio 3:5.

\subsection{The Fibonacci and Lucas sequence}

The relationship of these ratios in the house is identified with the extreme and mean ratio geometrically incorporated in the regular pentagon. The ratios suggest a possible relationship with the Fibonacci sequence, in which each successive number is equal to the sum of the two preceding numbers, 1 , $1,2,3,5,8,13,21 \ldots$ and the Lucas sequence, $2,1,3$, $4,7,11,18,29 \ldots$ The ratios of successive numbers of both series converge to approximately 1.618 , which is known as the extreme and mean ratio. Continuing to the right in these sequences, the ratios get close to the Golden Ratio, which is 1.618 (Fig.6.).

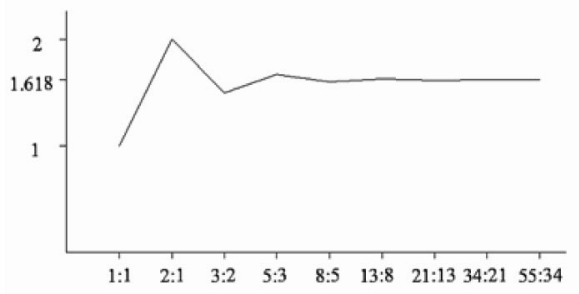

Fig.6. A Graph Showing its Successive Fibonacci Sequence Moving Closer to 1.618.

Its proportion with a regular geometrical pentagon can be identified in the following diagram (Fig.7.).

Ratios including $1: 1,4: 3,5: 3$, and 8:5 are certainly among these. Geometric constructions using existing

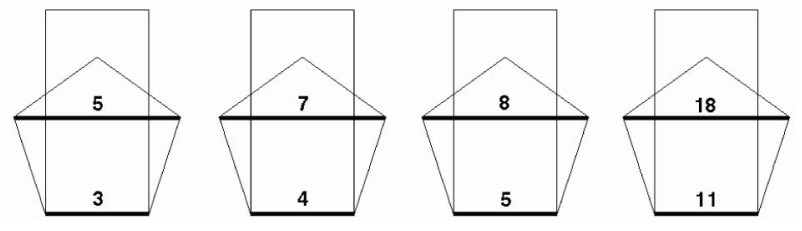

Fig.7. A Double Square and Pentagon with Root 5

ratios on the drawings derive new proportional ratios. By computing other ratios of the two series together, the remaining three ratios can be constructed (March, 1998b): 7:4 :: 2:1 = 8:7, 4:3 :: 3:2=9:8, and 18:11 :: $3: 2=12: 11$. All ratios are derived directly from other previously-used ratios. The implication of these newly constructed ratios with old ones is that all the room ratios become associated each other; thus, a ratio consistency is achieved. Also, it could be said that all of these related ratios are ubiquitous in the BraxtonShore house plans. This computation is delineated in the following diagrams (Fig.8.).
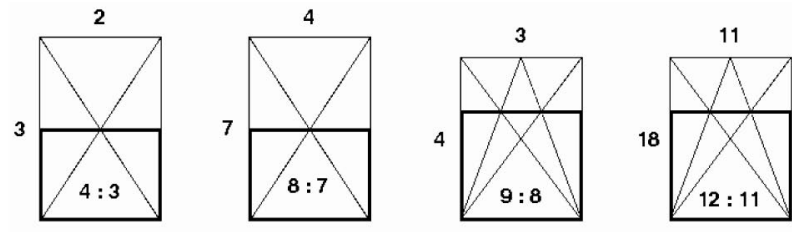

Fig.8. Geometric Construction of the Room Ratios

Thus, all room ratios of the project are suggestive of methods of computation coming out of the geometric and proportional construction. By this method, all other room ratios are constructed with regard to each other. Schindler might be aware of such ideas as he wrote, 'We must realize that "proportion" is not any more a simple mathematical relationship (Golden Rule, etc.) which can be applied universally in all buildings as it was in classical times.' However, it is incorrect to suppose Schindler derived his room ratios this way or mathematically. Although the architect had no particular belief of 'a simple mathematical relation' or 'Golden Rule', perhaps, some sort of computing procedure may have been involved in the architect's mind. Schindler could choose the total number of room dimensions in the project with reasons to reference proportions derived from simple geometry or to practical solutions to the problems of a particular design.

\subsection{Musical ratios}

Since Schindler employs a small number of units and a limited set of factions, any analysis of ratios and proportions will inevitably correspond to musical intervals. Again, it does not mean the musicality is intentional, but it is a necessary consequence as the relations of small numbers make it so. That is not to say that Schindler was unaware of musical proportion.

In his article, 'Reference Frames in Space,' Schindler expressed his musical thinking of the rhythmic arrangement of spatial organizations. His criticism 
of the 'Golden Rule' is followed by the concept of symphonic harmony - a definite musical analogy. Schindler explains his concept as follows: "Rhythm is a space relationship. It cannot be achieved by an arithmetical repetition of the same part but must be maintained by related spacings of parts, whether they are similar or not. As in music, such a rhythmic scheme may be simple repetition or the more subtle interlocking of several rhythms. It is practically impossible to maintain such an interlacing rhythmic play on a plan indicating dimensions by figure" (Schindler, 1946).

March's musical analogy in the analysis of the How house relies on this. In addition, when Schindler discussed proportion in his notes, he made reference to Claude Bragdon, saying 'SEE BRAGDON'S BOOKS.' Schindler might have referred to Bragdon's book, The Beautiful Necessity, originally published in 1910. A similar analogy between music and architecture is also inferred in the book. Claiming, 'architecture is frozen music,' Bragdon dedicated a whole chapter of his book to 'Frozen Music.' Bragdon explains, "Music depends primarily upon equal and regular divisions of time ... Architecture, correspondingly, implies the rhythmical division of space, and obedience to laws numerical and geometrical ... All architectural forms and arrangements which give enduring pleasure are in their essence musical. Every well-composed facade makes harmony in three dimensions; every good roof sings a melody against the sky" (Bragdon, 1910 and 1978).

Bragdon's discussion of musical notes follows with a vibrating string: intervals in connection with simple musical ratios, as in Robinson's articles (1898-1899). He further describes distinguishing characteristic of the ratios, either consonant or dissonant, connecting the ears to the eyes.

Before the Braxton-Shore house was designed, Schindler married his wife Pauline in Chicago, who majored in music from Smith College and may well have introduced him to new musical theory, including the Californian, Henry Cowell, Arnold Schoenberg, and John Cage. Of course, Schindler had a fundamental understanding of music scales since he had taken piano lessons for seven years in Vienna.

Earlier, Schindler's Austrian mentor, Adolf Loos, took Vitrivius' treatise to be his 'bible' according to the painter Oskar Kokoschka (1986). The chapter on harmony (1931) refers directly to musical theory. Trying to decipher the cryptic remarks in this chapter would lead a curious mind to a book such as Hermann Helmholtz's, Die Lehre von den Tonempfindungen, translated as On the Sensations of Tone as a Physiological Basis for the Theory of Music (1954) since this was the most available comprehensive modern work on the subject. The first edition was published in 1862; but many editions followed and the work stood as the 'authority' until well into the twentieth century.
All the ratios we attribute to Schindler's BraxtonShore house are found in musical divisions of a string of ratios, or musical ratios within an octave (Fig.9.). Room ratios in the project are equivalent to musical intervals like unison (1:1), second (9:8), fourth (4:3), sixth (5:3), and a minor sixth (8:5). Schindler himself shortly referred to musical ratios in his early discussion of proportion on his 1916 lecture notes.

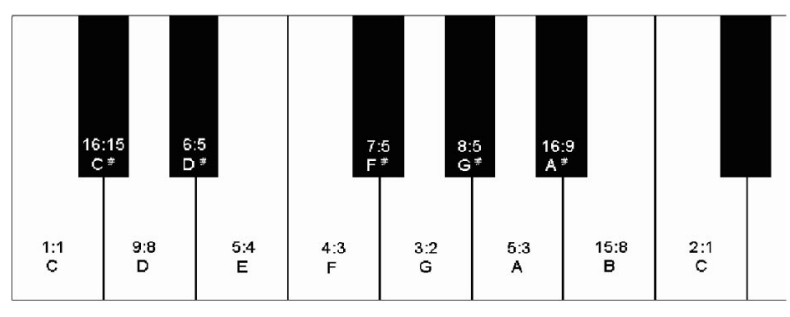

Fig.9. An Octave with Musical Ratios on a Piano Keyboard

The question arises, 'Are 8:7 and 12:11 musical ratios?' In fact, these ratios occur in early Greek tetrachords - enharmonic, chromatic, and diatonic, which are referenced in Vitruvius (1931) in the chapter 'Harmonic Principles'. In the chapter, 'equal diatonic' is Ptolemy's division of the ratio $4: 3$ (the tetrachord) into $12 / 11.11 / 10.10 / 9=4 / 3$. It appears that each interval approximates a tone. Ptolemy also has a 'tense chromatic': $7 / 6.12 / 11.22 / 21$ in which the last two intervals $12 / 11.22 / 21=8 / 7$.

However, the 'bible' on musical theory in Schindler's youth was Hermann Helmoltz's book. Helmholtz (1954) has a table in his book, Chapter 10, which indicates that in modern musical theory all ratios, $1: 1,2: 1,3: 2$, $4: 3,5: 4,6: 5,7: 6,8: 7$, and $9: 8$, occur and that the ratios $5: 3,7: 4,7: 5,8: 5,9: 5$, and $9: 7$ should be counted. Here, he only takes this table up to the number 9 , but he includes all possible ratios using numbers 1 - 9 between $1: 1$ and $2: 1$.

\section{Summary}

The proportional design of Schindler's BraxtonShore house has been analyzed with regard to the 'row' system, the Fibonacci and Lucas sequence, and musical ratios. This proportional analysis was based on hypothetic speculation rather than Schindler's recorded documentary evidence. Although speculative, the employed analytic method was valid in the sense that it presented the proportional relationship of rooms in the house and exposed their harmonic integrity. Schindler wrote, 'The house of the future is a symphony of "space forms" - each room a necessary and unavoidable part of the whole.' In the design, the architect's approach was extremely simple. The composition of various rooms did not have to follow a mere mathematical play of rules, but had to express its relations in size between rooms so as to form an 'organic unity': a whole composed of related parts in an orderly arrangement.

All in all, the observation leads to a conclusion that proportional relations of these ratios tie together in 
a cohesive whole in a single design, thus creating a complex design. Whether the design was intentional or arrived at by chance, R. M. Schindler must have a splendid sense of proportional eyes to project such a simple and rational system to a very complex spatial composition.

\section{Acknowledgements}

This work was supported by an INHA University Research Grant. The early draft of this paper was presented at the Matomium Conference, Brussels. The author is indebted to Professor Lionel March for his advice in carrying out this proportional analysis.

\section{References}

1) Bragdon C. $(1910,1978)$ The Beautiful Necessity, A Quest Book.

2) Gebhard D. (1971) Schindler. London: Thames and Hudson.

3) Granger F. (1931) Trs. Vitruvius on Architecture, Cambridge: Harvard University Press, Book V, Chapter IV.

4) Helmholtz H. $(1862,1954)$ On the Sensations of Tone as a Physiological Basis for the Theory of Music, New York: Dover Publications, Inc.

5) Kokoschka O. (1971) Ma Vie, (1971) French translation (Paris, 1986), p. 76.

6) March L. (1993a) Proportion is an Alive and Expressive Tool... In L. March and J. Sheine (Eds) RM Schindler: composition and construction. London: Academy Edition.

7) March L. (1993b) Dr. How's Magical Music Box. In L. March and J. Sheine (Eds) RM Schindler: composition and construction. London: Academy Edition.

8) March L. (2003) Rudolph M. Schindler: Space Reference Frame, Modular Coordination, and the 'Row'. Nexus Network Journal, vol. 5 no. 2.

9) March L. (1998a) Architectonics of Humanism. London: Academy Editions.

10) March L. (1998b) Architectonics of proportion: a shape grammatical depiction of classical theory. Planning and Design. 26: 91-100.

11) Park J. (1996) Schindler, Symmetry and the Free Public Library, 1920. Architectural Research Quarterly. 2: 72-83.

12) Park J. (2003) Rudolph M. Schindler: Proportion, Scale, and the 'Row'. Nexus Network Journal, vol. 5 no. 2.

13) Park J. and March L. (2003) Space architecture: Schindler's 1930 Braxton-Shore project. Architectural Research Quarterly (arq). 7: 51-62.

14) Robinson J. (1898-9) Principles of Architectural Composition. Architectural Record VIII, 1: 1-25; 2:181-223; 3: 297-331; 4: 434-465.

15) Sarnitz A. (1986) Proportion and Beauty - the Lovell Beach House by Rudolph Michael Schindler, Newport Beach, 1922-26. JSAH, 45: 374-388.

16) Sarnitz A (1988) R. M. Schindler-Architect, 1887-1953. New York: Rizzoli.

17) Schindler R (1946) Reference Frames in Space. Architect and Engineer, San Francisco 165: 10, 40, 44-45.

\section{Notes}

The Schindler archive is located in the Architectural Drawing Collection, University Art Museum, University of California at Santa Barbara (UCSB).

2 Schindler documented a series of lectures at the Church school in Chicago in a booklet of his handwritten notes. The lecture notes are housed in the Schindler Archive at UCSB. 